\title{
Магнитно-резонансная визуализация
}

\author{
влагалища и малого таза у женщин, \\ перенесших противоопухолевое лечение \\ по поводу рака женских половых органов
}

\author{
Аксенова С.П. *, Нуднов Н.В., Крейнина Ю.М. \\ ФГБУ “Российский научный центр рентгенорадиологии” Минздрава России, Москва, Россия

\section{Magnetic Resonance Imaging of the Vagina and Pelvic Organs in Women who Underwent Antitumor Treatment for Female Genital Cancer}

\author{
Aksenova S.P. *, Nudnov N.V., Kreynina Yu.M. \\ Russian Scientific Center of Roentgenoradiology, Moscow, Russia
}

Цель исследования: уточнение МР-семиотики неопухолевых изменений влагалища у женщин, перенесших лечение по поводу рака женских половых органов.

Материал и методы. В исследование включена 141 пациентка с подозрением на опухолевое поражение влагалища. У всех больных диагноз был подтвержден морфологически. По данным проведенного исследования опухолевое поражение влагалища установлено у $96(68,1 \%)$ пациенток, при этом первичный рак влагалища выявлен только у 11 (11\%) обследованных, наибольшее же число случаев составило вторичное поражение органа - 85 (89\%) наблюдений. Основой для дифференциальной диагностики явились результаты комплексного МР-исследования 45 (31,9\%) пациенток, у которых данных о наличии новообразования получено не было, но определяли посттерапевтические изменения в малом тазу. МР-исследования проводились на томографе Toshiba Vantage Atlas, 1,5 Т. Был использован протокол мультипараметрической МРТ для исследования органов таза, включавший в себя Т2ВИ с и без подавления сигнала от жировой ткани, Т1ВИ, диффузионно-взвешенные изображения, Т1ВИ с динамическим контрастным усилением. С целью умеренного расправления физиологической складчатости влагалища мы использовали МР-совместимый пластиковый аппликаTop.

Результаты. В процессе мониторинга изменения в виде фиброзирования тканей купола культи влагалища определялись в 51,9\% наблюдений, фиброзное утолщение стенок влагалища с сужением его просвета - в 18,5\% наблюдений, длительный отек тканей влагалища с умеренным изменением анатомо-топогра- фических взаимоотношений - в 73,3\% наблюдений. При этом у 12 (26,6\%) больных с клинически выраженным фиброзом стенок влагалища, стриктурами различной локализации, сопровождавшимися диспареунией, сухостью и повышенной кровоточивостью тканей влагалища, даже возможности осмотра были существенно ограничены, и МРТ явилась практически единственным полноценным методом дифференциальной диагностики.

Заключение. Знание анатомии оперированного влагалища позволило правильным образом интерпретировать выявляемые изменения во влагалище, производить детальную дифференцировку между неизмененными тканями купола культи влагалища и его опухолевым поражением.

Ключевые слова: купол культи влагалища, опухоли влагалища, магнитно-резонансная томография, рецидив, рак тела и шейки матки.

Ссылка для цитирования: Аксенова С.П., Нуднов Н.В., Крейнина Ю.М. Магнитно-резонансная визуализация влагалища и малого таза у женщин, перенесших противоопухолевое лечение по поводу рака женских половых органов. Медицинская визуализация. 2017; 21 (2): 131-139.

DOI: 10.24835/1607-0763-2017-2-131-139. $\star * \star$

Objective. To clarify MRI semiotics of non-neoplastic changes in the vagina in women undergoing treatment for cancer of the female genital organs.

Materials and methods. 141 patients with suspected tumor vaginal involvement were included in the study. In all 
the patients, the diagnosis was confirmed morphologically. According to the study, a tumor lesion of the vagina was established in $96(68.1 \%)$ patients, with primary vaginal cancer detected in only $11(11 \%)$ of the examined, the largest number of cases was a secondary organ damage - 85 (89\%). The basis for differential diagnosis was the results of a comprehensive MR-study of 45 (31.9\%) patients who did not receive data for the new formation, but determined the posttherapeutic changes in the small pelvis. MR-studies were performed on a Toshiba Vantage Atlas, 1.5T. A multiparametric MRI protocol was used for the study of pelvic organs, including T2WI with and without suppression of fat tissue signal, T1WI, diffusion-weighted images, T1WI with dynamic contrast enhancement. For the purpose of moderate expansion of the physiological folding of the vagina, we used an MP-compatible plastic applicator.

Results. In the course of monitoring changes in the form of fibrosis of the dome of the vaginal stump were determined in $51.9 \%$ of observations, fibrous thickening of the vaginal walls with a narrowing of its lumen - in $18.5 \%$ of observations, prolonged edema of the vaginal tissues with a moderate change in anatomo-topographic relationships - in 73.3\% of observations. In $12(26.6 \%)$ patients with clinically pronounced fibrosis of the vaginal walls, strictures of different localization, accompanied by dyspareunia, dryness and increased bleeding of the vaginal tissues, even the possibility of examination was significantly limited, and MRI was practically the only complete differential diagnostic method.

Conclusion. Knowledge of the anatomy of the operated vagina made it possible to correctly interpret the revealed changes in the vagina, to perform a detailed differentiation between the unchanged tissues of the dome of the vaginal stump and its tumor lesion.

Key words: dome of the vagina stump, vaginal tumors, magnetic resonance imaging, recurrence, endometrial and cervical cancer.

Recommended citation: Aksenova S.P., Nudnov N.V., Kreynina Yu.M. Magnetic Resonance Imaging of the Vagina and Pelvic Organs in Women who Underwent Antitumor Treatment for Female Genital Cancer. Medical visualization. 2017; 21 (2): 131-139.

DOI: $10.24835 / 1607-0763-2017-2-131-139$.

$$
\star \star \star
$$

\section{Введение}

Несмотря на то что влагалище является внутренним половым органом женщины, доступным для визуального и ручного исследования, частота ошибок в оценке характера изменений во влагалище довольно высока [1]. Правильная интерпретация данных особенно затруднена у больных, перенесших хирургическое и лучевое лечение [2-4]. Высокая частота инфильтративного и мультицентрического роста опухоли, нарушения анатомотопографических взаимоотношений органов и фиброзные изменения тканей после первичного лечения затрудняют адекватную и своевременную оценку определяемых изменений $[5,6]$. Высокие показатели информативности магнитно-резонансной томографии (МРТ) - 80-90\% в визуализации структур с минимальными плотностными характеристиками, в частности влагалища, матки, яичников, определяют приоритетное использование данного метода в диагностике опухолевой и неопухолевой патологии малого таза [7-9]. Незнание МР-картины оперированного таза и радиоиндуцированных изменений у женщин после специализированного противоопухолевого лечения приводит к неправильной интерпретации выявляемых изменений и диагностическим ошибкам $[10,11]$.

\section{Цель исследования}

Уточнение МР-семиотики посттерапевтических изменений влагалища у женщин, перенесших лечение по поводу опухолей органов женской репродуктивной системы.

\section{Материал и методы}

В исследование включена 141 пациентка с подозрением на опухолевое поражение влагалища. Исследование носило проспективный характер. У всех больных диагноз был подтвержден морфологически. По данным проведенного исследования опухолевое поражение влагалища установлено у $96(68,1 \%)$ пациенток, при этом первичный рак влагалища выявлен только у 11 (11\%) обследованных, наибольшее же число случаев составило вторичное поражение органа - 85 (89\%) паци-

Для корреспонденции: Аксенова Светлана Павловна - 117997 Москва, ул. Профсоюзная, д. 86. Российский научный центр рентгенорадиологии. Тел.: +7-926-372-47-69. E-mail: fabella@mail.ru

Аксенова Светлана Павловна - младший научный сотрудник научно-исследовательского отдела новых технологий и семиотики лучевой диагностики заболеваний органов и систем ФГБУ “Российский научный центр рентгенорадиологии” МЗ РФ, Москва; Нуднов Николай Васильевич - доктор мед. наук, профессор, заместитель директора по науке ФГБУ "Российский научный центр рентгенорадиологии" МЗ РФ, Москва; Крейнина Юлия Михайловна - доктор мед. наук, ведущий научный сотрудник лаборатории лучевой терапии научноисследовательского отдела инновационных технологий радиотерапии и химиолучевого лечения злокачественных новообразований ФГБУ "Российский научный центр рентгенорадиологии" МЗ РФ, Москва.

Contact*: Svetlana P. Aksenova - Profsoyuznaya str., 86, Moscow, Russia, 117997. Russian Scientific Center of Roentgenoradiology. Phone: +7-926-372-47-69. E-mail: fabella@mail.ru

Svetlana P. Aksenova- junior researcher of New Radiologic Technologies and Disease Semiotics Research Department of Russian Scientific Center of Roentgenoradiology, Moscow, Russia; Nikolay V. Nudnov - doct. of med. sci., professor, Deputy Director of Russian Scientific Center of Roentgenoradiology, Moscow, Russia; Yulia M. Kreynina - doct. of med. sci., leading researcher of Innovative Technologies in Radiotherapy and Chemoradiation Research Department of Russian Scientific Center of Roentgenoradiology, Moscow, Russia. 
енток, из них 42 (49\%) с первичным раком вульвы, шейки и тела матки с распространением на влагалище и 43 (51\%) с рецидивными опухолями с поражением влагалища.

Основой для дифференциальной диагностики явились результаты комплексного МР-исследования 45 (31,9\%) пациенток, проведенного в сроке от 2 до 60 мес после окончания специализированного противоопухолевого лечения, у которых данных о наличии новообразования получено не было, но определяли посттерапевтические изменения в малом тазу. Данные МР-исследований 45 пациенток стали основой для выявления закономерностей МР-семиотики посттерапевтических изменений влагалища и малого таза, которым и посвящена данная статья.

МР-исследования у всех больных проводились по комплексному протоколу, включавшему в себя Т2-взвешенные изображения (ВИ) в трех взаимно перпендикулярных плоскостях, Т2ВИ с подавлением сигнала от жировой ткани в аксиальной плоскости, Т1ВИ в сагиттальной и аксиальной плоскости, диффузионно-взвешенные изображения (ДВИ) в аксиальной плоскости, Т2ВИ с МР-совместимым эндовагинальным аппликатором, Т1ВИ с динамическим контрастным усилением. Ввиду того что при разметке стандартных аксиальных проекций нижняя треть влагалища зачастую в поле обзора не попадает, мы использовали разметку Т2ВИ с большим полем обзора (FOV $=50 \times 30$ cм) и толщиной среза не более 4 мм, при которой нижним краем являлась ягодичная складка. Для нивелирования частичного объемного эффекта ориентация аксиальных срезов производилась перпендикулярно оси влагалища. С целью умеренного расправления физиологической складчатости влагалища мы использовали МР-совместимый пластиковый аппликатор. Аппликатор диаметром 14 мм позволял обозначить просвет влагалища без нарушения анатомо-топографических взаимоотношений между опухолью и окружающими структурами.

К моменту проведения исследования 37 (82\%) женщин из 45 обследованных с посттерапевтическими изменениями влагалища в анамнезе полу- чали хирургическое лечение и у 8 (18\%) больных было проведено химиолучевое лечение по поводу опухолей женских половых органов (таблица).

\section{Результаты}

Фиброзные изменения стенок влагалища определялись у 8 (18\%) неоперированных пациенток с опухолью матки, прошедших МР-исследование после окончания химиолучевого лечения. У этих пациенток отмечалось циркулярное утолщение и снижение МР-сигнала от стенки верхней трети влагалища, длительное накопление контрастного препарата в данной зоне. Стоит отметить, что у всех пациенток было выявлено сужение просвета влагалища, в связи с этим у 4 из них не прослеживалась продольная складчатость в средней трети. Наилучшая визуализация вышеописанных изменений определялась на сагиттальных и аксиальных сканах. При анализе ADC-карт данных о нарушении скорости диффузии в проекции измененной стенки влагалища выявлено не было. Показатели ИКД в данных наблюдениях составил в среднем 1,87 $\mathrm{Mm}^{2} / \mathrm{c} \cdot 10^{-3}$.

Анализ МР-изображений органов малого таза у оперированных больных существенно отличался от неоперированных. Сохранившееся влагалище укорочено, заканчивается слепо, на месте шейки матки - рубец. При выраженных фиброзно-спаечных процессах купол культи влагалища был подтянут к петле сигмовидной кишки, в этих случаях влагалище было уплощенным и вытянутым в вертикальном направлении. Оценить вагинальный рубец позволяли изображения, ориентированные в сагиттальной плоскости. Структурно рубец может быть гипертрофирован и определяться на сагиттальных изображениях в виде шара и баллона, вытянутого вертикально, однако чаще рубец сглажен и визуализируется в виде умеренного утолщения дистального конца влагалища. Область оперативного вмешательства на коронарных срезах приобретает форму “глубокой чаши" за счет фиброзных тяжей с латеральных сторон, дно которой представлено собственно культей (рис. 1, а). На этом уровне на аксиальных срезах будут визуализироваться две зоны гипоинтенсивного МР-сиг-

Вид первичного лечения у пациенток с посттерапевтическими изменениями влагалища

\begin{tabular}{|c|c|c|c|c|}
\hline \multicolumn{5}{|c|}{ Вид лечения, полученного в анамнезе $(n=45)$} \\
\hline $\begin{array}{c}\text { хирургическое } \\
\text { лечение }\end{array}$ & $\begin{array}{c}\text { химиолучевое } \\
\text { лечение }\end{array}$ & $\begin{array}{r}\text { комбиниро } \\
\text { (n }\end{array}$ & е лечение & $\begin{array}{c}\text { комплексное лечение } \\
\text { (хирургическое лечение } \\
\text { + ЛТ + XТ) }\end{array}$ \\
\hline 1 & 8 & $\begin{array}{l}\text { хирургическое } \\
\text { лечение } \\
+ \text { XТ - } 5\end{array}$ & $\begin{array}{c}\text { хирургическое } \\
\text { лечение } \\
+ \text { ЛТ - } 6\end{array}$ & 25 \\
\hline
\end{tabular}

Примечание. ЛТ - лучевая терапия, ХТ - химиотерапия. 

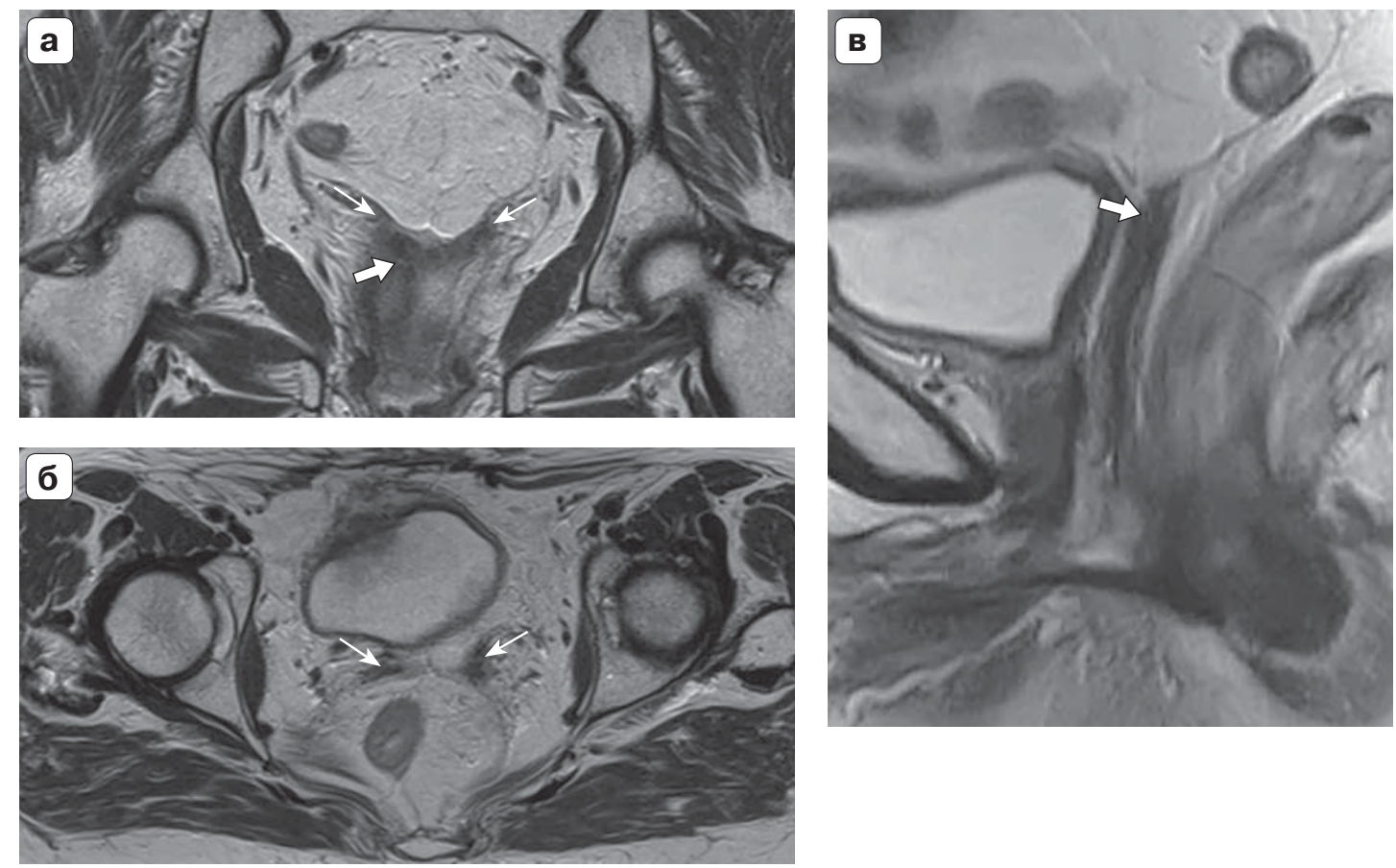

Рис. 1. МР-томограммы органов малого таза больной после радикальной гистерэктомии (купол влагалища отмечен стрелкой, фиброзные тяжи с латеральных сторон - тонкими стрелками). а - Т2ВИ в коронарной плоскости; б - Т2ВИ в аксиальной плоскости; в - Т2ВИ в сагиттальной плоскости.

нала, соответствующие перевязанному сосудистому пучку и связкам матки (рис. 1, б).

Размеры влагалища и его купола отличаются у разных пациенток, поскольку они зависят от возраста, степени атрофических изменений, типа операции и дозы облучения, если оно проводилось. Размер купола также зависит от особенностей хирургического вмешательства. Он будет определяться объемом тканей, вовлеченных в швы, и типом шва, наложенного для закрытия просвета влагалища.

Для нормальных, с онкологической точки зрения, послеоперационных изменений органов малого таза после хирургического и комбинированного лечения опухолей женской репродуктивной системы характерно наличие различной степени выраженности фиброзных изменений в зоне выполненных вмешательств с типичными визуальными признаками (дополнительное образование с неровными, четкими контурами либо тяжистость, уплотнение клетчатки и тканей в зоне вмешательства).

В норме купол культи влагалища на Т2- и Т1ВИ визуализировался гипоинтенсивным по сравнению с окружающей жировой тканью в связи с наличием в нем значительного количества фиброзной ткани. При наличии в куполе культи металлических скоб определялись артефакты, затрудняющие визуализацию верхних отделов влагалища.
Иногда в центральных отделах купола культи влагалища встречалось ограниченное скопление серозной жидкости, сохранившееся после оперативного вмешательства или лучевого лечения и представляющее собой серозоцеле (рис. 2).

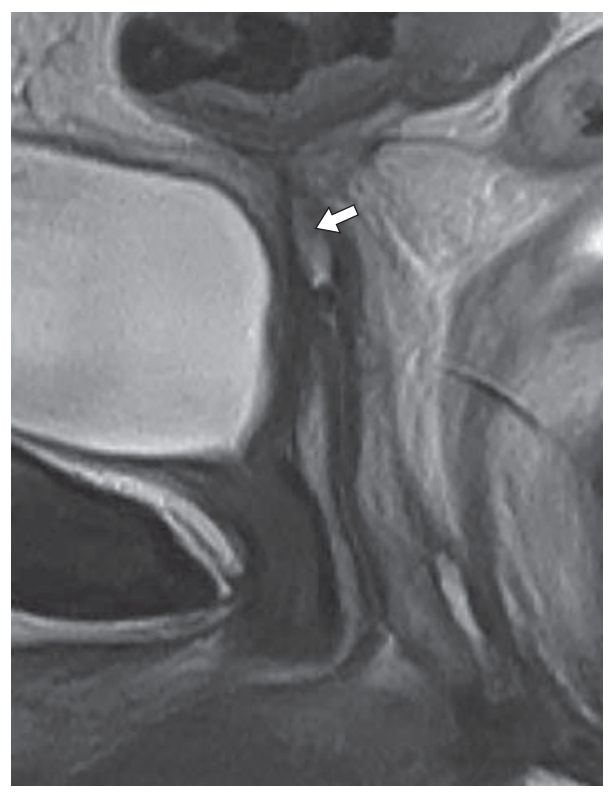

Рис. 2. МР-томограмма органов малого таза больной после комбинированного лечения. Стрелкой отмечено серозоцеле в куполе культи влагалища. 

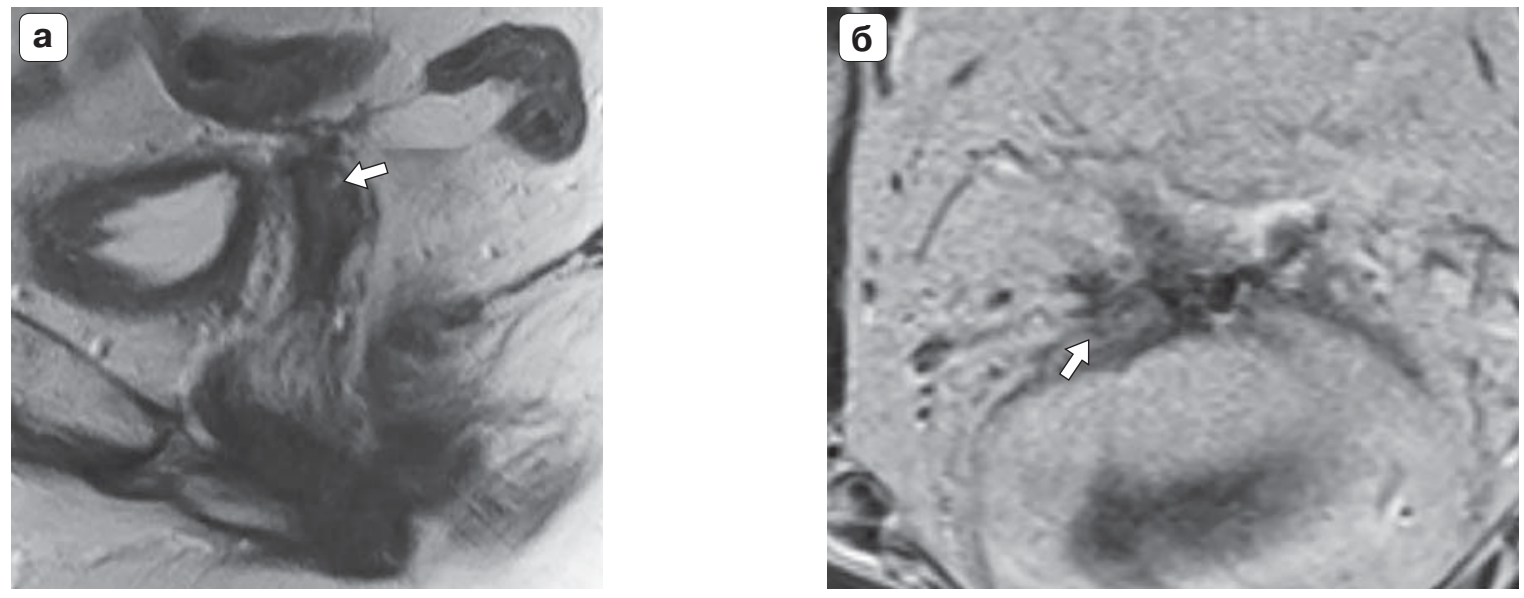

Рис. 3. МР-томограммы органов малого таза больной раком эндометрия lb стадии с рецидивом в куполе культи влагалища. а - Т2ВИ в сагиттальной плоскости; б - Т2ВИ в аксиальной плоскости. Визуализируются асимметрия купола культи влагалища (D > S), появление участка неоднородно повышенного МР-сигнала, соответствующего опухолевой ткани (стрелка).

В процессе мониторинга изменения в виде фиброзирования тканей купола культи влагалища определялись в 51,9\% наблюдений, фиброзное утолщение стенок влагалища с сужением его просвета - в 18,5\% , длительный отек тканей влагалища с умеренным изменением анатомо-топографических взаимоотношений - в 73,3\% наблюдений. При этом у 12 (26,6\%) больных с клинически выраженным фиброзом стенок влагалища, стриктурами различной локализации, сопровождавшимися диспареунией, сухостью и повышенной кровоточивостью тканей влагалища, даже возможности осмотра были существенно ограничены, и МРТ явилась практически единственным полноценным методом дифференциальной диагностики.

При МР-исследовании фиброзно-спаечные изменения купола культи влагалища характеризовались наличием гипоинтенсивных тяжей от культи влагалища в прилежащие ткани, в первую очередь - к петле сигмовидной кишки и к стенкам таза, резко сниженным МР-сигналом во всех импульсных последовательностях. МР-семиотика фиброзных изменений купола культи влагалища характеризовалась наличием зоны гипоинтенсивного МР-сигнала в Т2- и Т1ВИ вокруг тканей культи, без признаков нарушения скорости диффузии и накоплением парамагнетика преимущественно в венозную и отсроченную фазы динамического контрастного усиления.

Постлучевой отек, как реакция тканей на проведенную лучевую терапию, определялся отчетливо в $73 \%$ случаев в сроки наблюдения от 1,5 до 12-30 мес после окончания курса лечения в виде равномерного или неравномерного утолщения слизистого слоя стенки влагалища с сохранением мышечного слоя, характеризующегося повышенным МР-сигналом на Т2 с и без подавления сигнала от жировой ткани, что являлось одним из основных дифференциальных критериев для ранней диагностики рецидива опухоли в этой зоне. Отек клетчатки таза (60\%) наилучшим способом визуализировался на изображениях с подавлением сигнала от жировой ткани (T2BИfatsat) и выявлялся в виде повышения интенсивности сигнала от жировой клетчатки. При диффузном отеке паракольпийной клетчатки (71\%) отмечалось интенсивное, но в целом равномерно-интенсивное накопление парамагнетика в отсроченную фазу динамического контрастного усиления.

Особую трудность составляла дифференциальная диагностика фиброзных изменений и отека в куполе культи влагалища с начальными проявлениями продолженного роста опухоли, что было определено при анализе Т2ВИ в 68\% наблюдений, T2fatsat в 74\% наблюдений, ДВИ в 80\% наблюдений, динамического контрастного усиления в $85 \%$ случаев. При рецидиве опухоли в культе влагалища в 95\% наблюдений определялось асимметричное утолщение рубца, появление на фоне гипоинтенсивных фиброзных тканей зоны повышенного MP-сигнала в Т2ВИ и T2fatsat, характеризующейся повышенным МР-сигналом на ДВИ и интенсивным накоплением парамагнетика в артериальную и венозную фазы динамического контрастного усиления (рис. 3).

Для ДВИ в целом характерна высокая степень достоверности выявления патологических изменений, подозрительных на локорегионарный рецидив опухолей женских половых органов с поражением влагалища. Не выявленные при использо- 

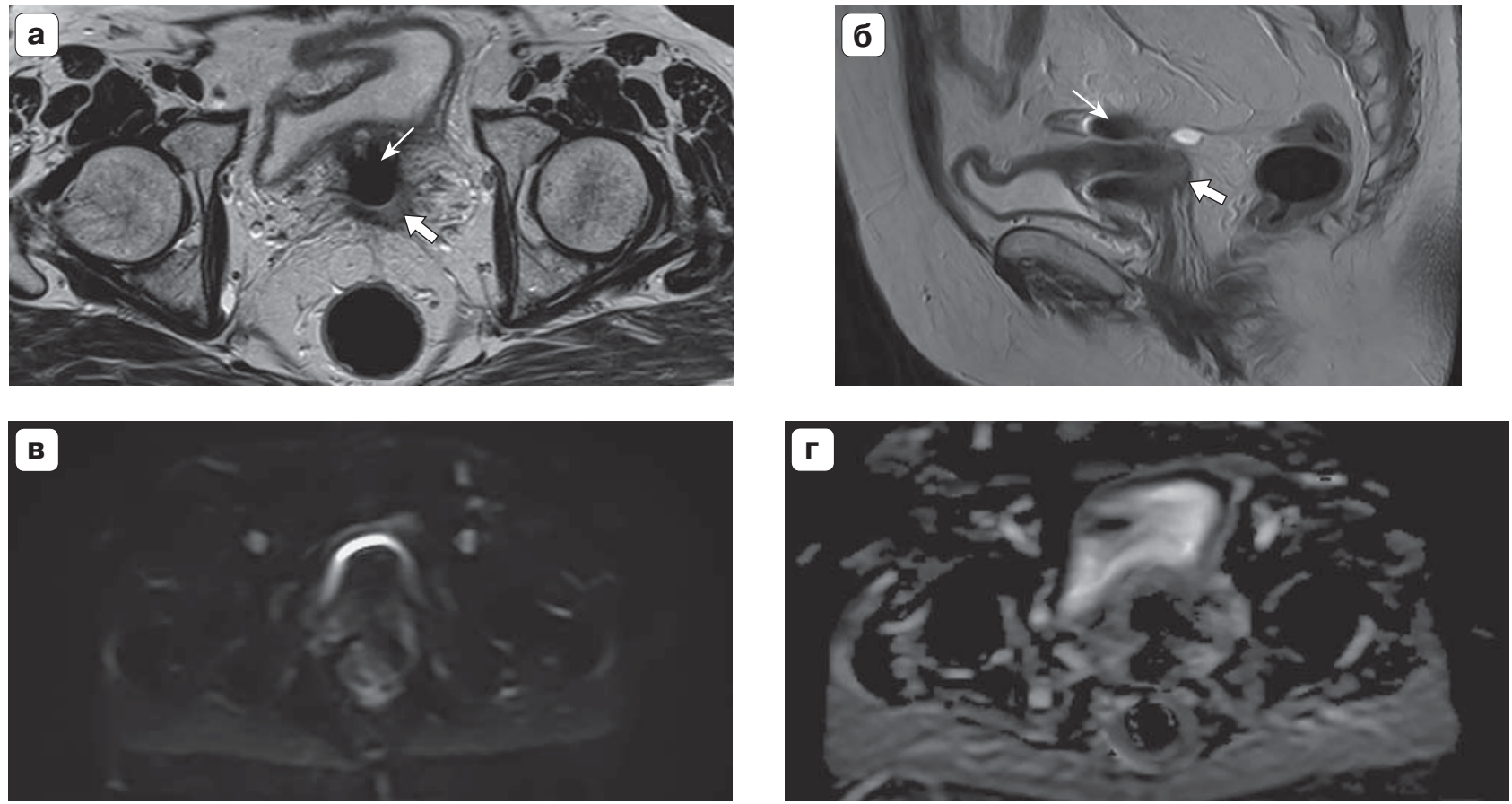

Рис. 4. МР-томограммы рецидива рака шейки матки в куполе культи влагалища. а - Т2ВИ, аксиальная проекция, опухоль отмечена стрелкой; б - Т2ВИ, сагиттальная проекция; в - ДВИ, изотропное изображение в аксиальной плоскости; г - ДВИ, ADC-карта. На фоне выраженных артефактов от металлических швов в проекции купола культи визуализация и оценка ДВИ невозможны (артефакты отмечены тонкой стрелкой).
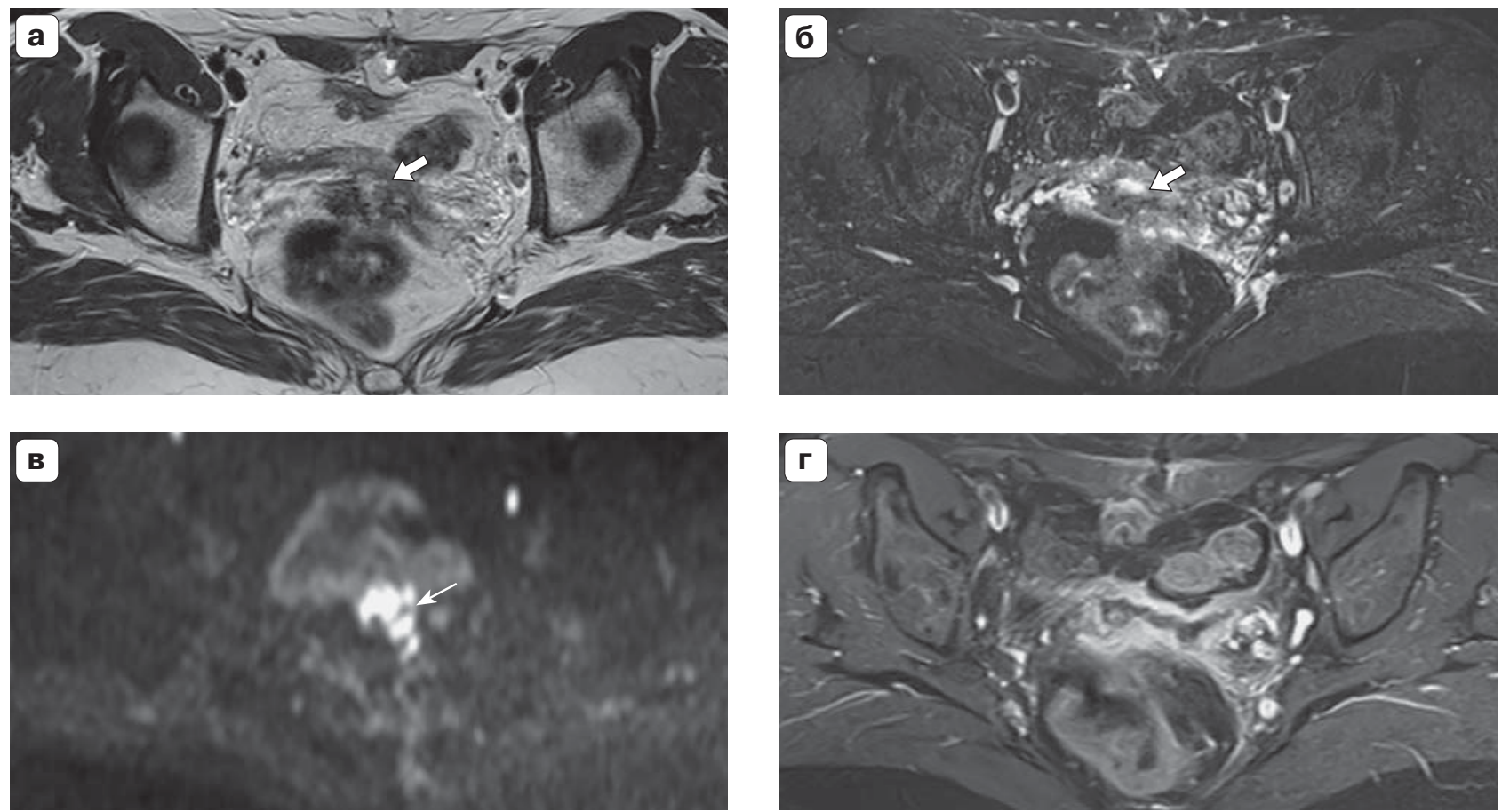

Рис. 5. МР-томограммы воспалительного инфильтрата в куполе культи влагалища и при культевой клетчатке у пациентки после хирургического лечения рака шейки матки. а - Т2ВИ, аксиальная проекция, визуализируется утолщение стенки верхней трети влагалища с незначительной потерей ее дифференцировки (стрелка); б - Т2fatsat ВИ, аксиальная проекция; в - ДВИ, изотропное изображение в аксиальной плоскости, область ограничения диффузии в проекции культи влагалища (тонкая стрелка); г - Т1ВИ после динамического контрастного усиления, сниженное накопление парамагнетика в проекции выявленных изменений. 

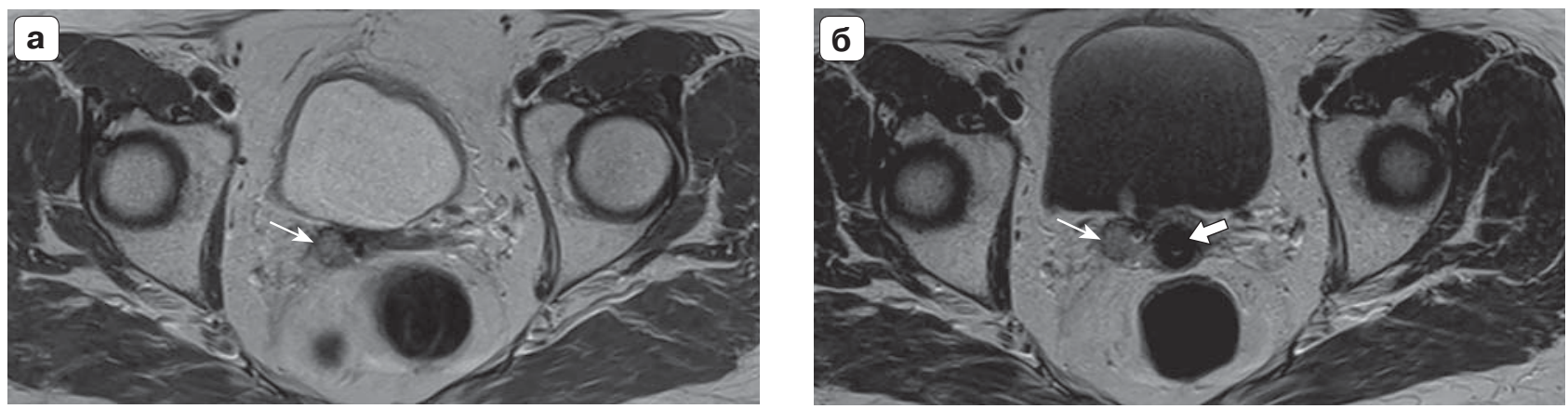

Рис. 6. МР-томограммы больной раком эндометрия с рецидивом опухоли во влагалище (тонкая стрелка). а - Т2ВИ в аксиальной плоскости; б - Т2ВИ в аксиальной плоскости с введенным во влагалище аппликатором (стрелка).

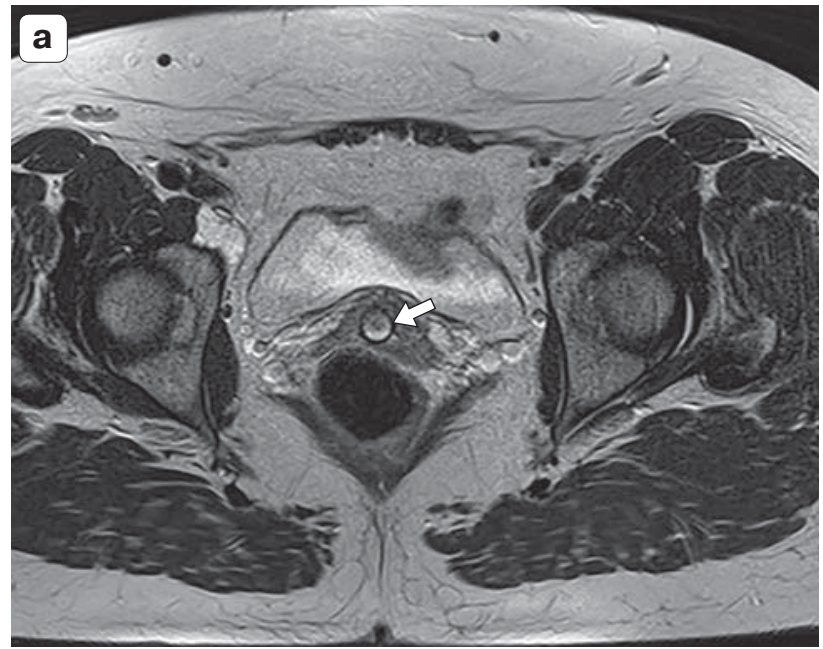

вании ДВИ рецидивы в области культи влагалища были обусловлены наличием артефактов от металлических швов, наложенных для закрытия просвета влагалища (рис. 4).

Определенную сложность в дифференциальной диагностике представляли случаи возникновения небольшой рецидивной опухоли в толще купола культи влагалища, особенно у пациенток с "большим" рубцом после оперативного или лучевого лечения. При анализе "нативного" исследования, включающего Т2ВИ, Т2fatsatBИ, Т1ВИ, на фоне фиброзных изменений рецидив не визуализируется и может быть пропущен врачом-диагностом. Применение ДВИ в 85\% случаев позволяло провести дифференциальную диагностику и своевременно диагностировать опухолевое поражение влагалища.

Наибольшие сложности в интерпретации результатов исследования возникали в $6 \%$ случаев, когда имели место постоперационные и постлучевые воспалительные изменения в малом тазу с наличием активных грануляций и абсцессов, в том

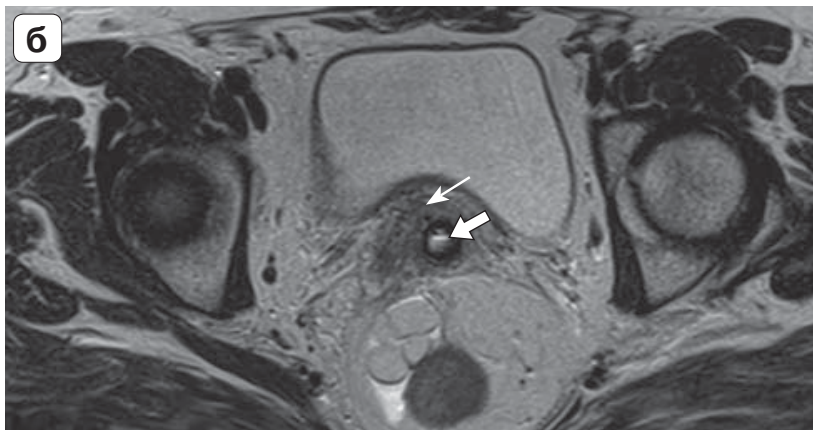

Рис. 7. МР-томограммы у больных с опухолевым поражением верхней трети влагалища. а - Т2ВИ в аксиальной плоскости с введенным во влагалище аппликатором (стрелка): б - Т2ВИ в аксиальной плоскости (стрелка - аппликатор, тонкая стрелка - опухолевая инфильтрация). На обоих изображениях опухоль циркулярно инфильтрирует стенку влагалища и прилежащую клетчатку.

числе при несостоятельности швов культи влагалища. Для данных видов изменений, так же как и для злокачественных опухолей, характерны ограничение диффузии на изотропных изображениях и визуализация сниженного MP-сигнала на ADCкартах (рис. 5).

Хорошие результаты были получены при анализе пациенток с подозрением на поражение купола культи влагалища $(\mathrm{n}=88 ; 62,4 \%)$. Аппликатор заполнял полость влагалища и в умеренной степени расправлял свод купола культи, который нередко проседал и создавал впечатление его утолщения при анализе импульсной последовательности без эндовагинального аппликатора (рис. 6).

Использование аппликатора к тому же позволяло более четко определить локализацию и протяженность заболевания, так как сам являлся дополнительной меткой. Так, к примеру, при правильном введении аппликатора у оперированных больных "до упора" - при поражении верхних отделов влагалища дистальный конец аппликатора обозначал расправленный купол культи влагалища (рис. 7). 


\section{Обсуждение}

Изменения тканей, обусловленные воздействием лучевой и химиотерапии, довольно хорошо выявляются с помощью МРТ. Изменение структуры опухолевой и окружающих тканей связано с замещением их фиброзной тканью, содержащей меньшее количество внутриклеточной жидкости. Данная особенность фиброзной ткани характеризуется меньшим временем релаксации и выявляется на конечных изображениях более сниженным МР-сигналом на Т2ВИ относительно первичной опухоли, не подвергшейся воздействию ионизирующего облучения $[5,6]$. Нами также отмечено, что интенсивность сигнала на Т2ВИ будет немного снижена у рецидивных опухолей и при прогрессировании опухоли влагалища у пациенток с лучевой терапией в анамнезе.

В настоящем исследовании, как и по данным большинства авторов, анатомия влагалища лучше всего визуализировалась на мультипланарных Т2ВИ благодаря использованию в протоколе турбо-спин-эхо последовательности (2D turbo spin echo - TSE) $[12,13]$. Так, на Т2ВИ четко определяются стенки влагалища, его своды и окружающие органы и структуры. Использование косоаксиальной Т2ВИ проекции с высоким разрешением, ориентированной перпендикулярно длинной оси влагалища, представляется наиболее значимой последовательностью для детальной оценки опухоли влагалища и ее распространения на паравагинальную клетчатку, что также подмечено в последних работах, посвященных МР-диагностике поражений влагалища $[14,15]$. Т2ВИ в коронарной проекции используются в большинстве случаев для визуализации стенок таза, особенно при больших размерах опухоли.

Идея дополнительного контрастирования просвета влагалища в ходе МРТ разрабатывалась целым рядом отечественных и зарубежных специалистов, однако наибольшую известность получили работы Н.А. Рубцовой [9] и Р. Young [16]. При контрастировании влагалища мы считали крайне важным создание условий для адекватной визуализации влагалищной трубки на всем протяжении при сохранении естественной анатомии и топографии органа, техническую доступность метода. В связи с этим было предложено и успешно апробировано применение эндовагинального МР-совместимого аппликатора для диагностики влагалища, обладающего вышеуказанными преимуществами.

\section{Заключение}

Анализ МР-исследований пациенток после специализированного противоопухолевого лече- ния, в частности хирургического и лучевого, позволил выявить и описать лучевую семиотику оперированного влагалища. Знание анатомии оперированного влагалища в проведенном исследовании позволяло правильным образом интерпретировать выявляемые изменения во влагалище, производить детальную дифференцировку между неизмененными тканями купола культи влагалища и его опухолевым поражением.

\section{Список литературы}

1. Виноградова Л.В. Диагностика и профилактика опухолей влагалища. Российский медицинский журнал. 2005; 1: 28-30.

2. Березовская Т.П., Спицын А.Ф., Михайлова Е.В., Валькова В.Н. Магнитно-резонансная характеристика постлучевых изменений в области малого таза у женщин. Магнитный резонанс в медицине и биологии: Тезисы докладов международной конференции. Казань, 1997. 95 с.

3. Шавладзе 3.Н., Березовская Т.П., Прошин А.А. Магнитно-резонансное изображение радиоиндуцированных изменений в области малого таза после лучевой терапии злокачественных опухолей. Медицинская визуализация. 2007; 5: 76-90.

4. Каприн А.Д., Галкин В.Н., Иванов С.А., Солодкий В.А., Титова В.А. Брахитерпия в лечении рака влагалища. Biomedical Photonics. 2016; 5 (1): 22-26.

5. Sugemura K., Carrington B.M., Quivey J.M., Hricak H. Postirradiation changes in the pelvis: assessment with MR imaging. Radiology. 1990; 175 (6): 805-813.

6. Fletcher B.D., Hanna S.L., Kun L.E. Changes in MR signal intensity and contrast enhancement of therapeutically irradiated soft tissue. Magn. Reson. Imaging. 1990; 8: 771-777.

7. Кудреватых Е.В., Тер-Арутюнянц С.А., Мершина Е.А., Синицын В.Е. Магнитно-резонансная томография в диагностике и оценке результатов комбинированного и химиолучевого лечения рака шейки матки. Кубанский научный медицинский вестник. 2010; 6: 65-69.

8. Рубцова Н.А., Новикова Е.Г., Синицын В.Е. Роль диффузионно-взвешенной магнитно-резонансной томографии в диагностике рецидивных опухолей матки. Радиология-практика. 2012; 4: 41-54.

9. Рубцова Н.А. Магнитно-резонансная томография в диагностике, планировании и оценке эффективности лечения рака шейки и тела матки: Дисс. ... д-ра мед. наук. М., 2013. 216 с.

10. Blomlie V., Roftstad E.K., Tvera K., Lien H.H. Noncritical soft tissues of female pelvis: serial MR imaging before, during and after radiation therapy. Radiology. 1996; 199 (2): 461-468.

11. Richardson M.L., ZinkBrody G.C., Patten R.M., Koh W.J, Conrad E.U. MR characterization of postirradiation soft tissue edema. Skeletal. Radiol. 1996; 25: 537-543.

12. Devine C., Szklaruk J., Tamm E.P. Magnetic Resonance Imaging in the Characterization of Pelvic Masses. Seminars in Ultrasound. CT and MRI. 2005; 26: 172-204.

13. Hosseinzadeh K., Heller M.T., Houshmand G. Imaging of the Female Perineumin Adults. RadioGraphics. 2012; 32 (4): 129-168. 
14. Hricak H., Chang Y.C., Thurnher S. Vagina: evaluation with MR imaging. Part I. Normal anatomy and congenital anomalies. Radiology. 1988; 169: 169-174.

15. Parikh J.H., Barton D.P.J., Ind T.E.J., Aslam Sohaib S. MR Imaging Features of Vaginal Malignancies. RadioGraphics. 2008; 28 (1): 49-63.

16. Young P., Daniel B., Sommer G., Kim B, Herfkens R. Intravaginal gel for staging of female pelvic cancerspreliminary report of safety, distention, and gel-mucosal contrast during magnetic resonance examination. J. Comput. Assist. Tomogr. 2012; 36 (2): 253-256.

\section{References}

1. Vinogradova L.V. Diagnosis and prevention of vaginal tumors. Rossiyskiy meditsinskiy zhurnal. 2005; 1: 28-30. (In Russian)

2. Berezovskaya T.P., Spitsyn A.F., Mikhailova E.V., Valkova V.N. Magnetic resonance characterization of post-radial changes in the pelvic area in women. Magnetic resonance in medicine and biology: Abstracts of the international conference. Kazan, 1997. 95 p. (In Russian)

3. Shavladze Z.N., Berezovskaya T.P., Proshin A.A. Magnetic resonance image of radioinduced changes in the pelvic region after radiation therapy of malignant tumors. Medical Visualization. 2007; 5: 76-90. (In Russian)

4. Kaprin A.D., Galkin V.N., Ivanov S.A., Solodky V.A., Titova V.A. Brachyterpia in the treatment of vaginal cancer. Biomedical Photonics. 2016; 5 (1): 22-26. (In Russian)

5. Sugemura K., Carrington B.M., Quivey J.M., Hricak H. Postirradiation changes in the pelvis: assessment with MR imaging. Radiology. 1990; 175 (6): 805-813.

6. Fletcher B.D., Hanna S.L., Kun L.E. Changes in MR signal intensity and contrast enhancement of therapeutically irradiated soft tissue. Magn. Reson. Imaging. 1990; 8: 771-777.
7. Kudrevatykh E.V., Ter-Harutyunyants S.A., Mershina E.A., Sinitsyn V.E. Magnetic resonance imaging in diagnosis and evaluation of combined and chemoradiation treatment of cervical cancer. Kubanskiy nauchniy meditsinskiy vestnik. 2010; 6: 65-69. (In Russian)

8. Rubtsova N.A., Novikova E.G., Sinitsin V.E. The role of diffusion-weighted magnetic resonance imaging in the diagnosis of recurrent tumors of the uterus. RadiologiyaPraktika. 2012; 4: 41-54. (In Russian)

9. Rubtsova N.A. Magnetic resonance imaging in the diagnosis, planning and evaluation of the effectiveness of treatment of cervical and endometrial cancer: Diss. ... doct. of med. sci. Moscow, 2013. 216 p. (In Russian)

10. Blomlie V., Roftstad E.K., Tvera K., Lien H.H. Noncritical soft tissues of female pelvis: serial MR imaging before, during and after radiation therapy. Radiology. 1996; 199 (2): 461-468.

11. Richardson M.L., ZinkBrody G.C., Patten R.M., Koh W.J, Conrad E.U. MR characterization of postirradiation soft tissue edema. Skeletal. Radiol. 1996; 25: 537-543.

12. Devine C., Szklaruk J., Tamm E.P. Magnetic Resonance Imaging in the Characterization of Pelvic Masses. Seminars in Ultrasound. CT and MRI. 2005; 26: 172-204.

13. Hosseinzadeh K., Heller M.T., Houshmand G. Imaging of the Female Perineumin Adults. RadioGraphics. 2012; 32 (4): 129-168.

14. Hricak H., Chang Y.C., Thurnher S. Vagina: evaluation with MR imaging. Part I. Normal anatomy and congenital anomalies. Radiology. 1988; 169: 169-174.

15. Parikh J.H., Barton D.P.J., Ind T.E.J., Aslam Sohaib S. MR Imaging Features of Vaginal Malignancies. RadioGraphics. 2008; 28 (1): 49-63.

16. Young P., Daniel B., Sommer G., Kim B, Herfkens R. Intravaginal gel for staging of female pelvic cancerspreliminary report of safety, distention, and gel-mucosal contrast during magnetic resonance examination. J. Comput. Assist. Tomogr. 2012; 36 (2): 253-256. 